\title{
XXXVIII. The relation of electrode fall in gases to the contact potential series
}

\section{Clarence A. Skinner Ph.D.}

To cite this article: Clarence A. Skinner Ph.D. (1904) XXXVIII. The relation of electrode fall in gases to the contact potential series, Philosophical Magazine Series 6, 8:45, 387-400, DOI: 10.1080/14786440409463207

To link to this article: http://dx.doi.org/10.1080/14786440409463207

曲 Published online: 15 Apr 2009.

Submit your article to this journal $\sqsubset \pi$

Џ Article views: 3

Q View related articles $\square$

Citing articles: 5 View citing articles 5 
[Note (June 12th). - In a letter to 'Nature' of June 9th Prof. Nagaoka states that his system is not electrically neutral, but that the central charge is very large compared to the total charge of the ring; the remaining negative electrons necessary to make the whole system neutral are left out of account. This no doubt renders part of my criticism inapplicable, because by sufficiently increasing the central charge the ring can certainly be made stable; but is this allowable?

It is not clear that the negative electrons outside the ring can be left out of account in discussing the ring, for their charge is comparable in amount with the central charge; let us however assume, with Prof. Nagaoka, that they can. The equation of steady motion, (11) p. 450 , gives $\omega^{2} \fallingdotseq \mathrm{S}$, for $K$ is small because the negative electrons of the ring are few. With $\mathrm{S}=\frac{\nu e^{2}}{m a^{3}}$ we $\operatorname{get} \omega^{2} a^{2}=\frac{\nu e^{2}}{m a} ; \omega a$ is the velocity of the ring: this must be less than the velocity of light, else the problem is fundamentally altered ; with the usual values of $a, \frac{e}{m}$, and $e$, this gives $v<50,000$. Next, the equation (12) p. 450 gives for the imaginary frequency $-n^{2}=6 \mu \mathrm{J}$, whence

$$
\sqrt{-1} \frac{n}{\omega}=\sqrt{\frac{3 \mathrm{~J}}{v}}
$$

for a ring of 10 electrons $\mathrm{J} \fallingdotseq 34$, and with $\nu=50,000$ we get

$$
\sqrt{-1} \frac{n}{\omega} \fallingdotseq \frac{1}{20}
$$

in other words, the disturbance would increase $2 \cdot 7$ fold in about 3 revolutions. The system is again far too unstable.] Yours faithfully,

G. А. Sснотт.

XXXVIII. The Relation of Electrode Fall in Gases to the Contact Potential Series. By Clarence A. Skinner, Ph.D., Assistant Professor of Physics in the University of Nebraska, Lincoln*.

TN a former paper $\dagger$ the writer suggested that the series of metals, obtained when these were arranged according to the magnitude of the fall of potential at the electrodes when the glow-discharge passes through a rarefied gas, is closely related to the contact-potential series.

* Communicated by the Author.

$\dagger$ Phil. Mag. [6] ii. p. 637 (1901) 
In this paper are presented the results of experiments made to study this relation. The hypothesis is : The fall of the potential at the cathode in a given gas decreases as the electropositive value of the metal increases; the anode fall, on the other hand, decreases as the electronegative value of the metal increases.

\section{Plan and Preparation.}

The metals tested were mainly chosen with reference to their position in the contact-potential series. They were: platinum, silver, gold, copper, steel, nickel, bismuth, antimony, tin, lead, cadmium, zinc, aluminium, and magnesium. The gases used were: hydrogen, on account of the great difference it gives between the cathode-fall of platinum and aluminium; nitrogen, because of its chemical neutrality; and oxygen, because of the vital relation, in theory, between the contact potential of the metal and its affinity for oxygen.

The plan of procedure was to measure in the given gas the electrode fall of all the metals under, so far as possible, exactly the same conditions. It was found impossible to obtain the fall sufficiently definite by testing first one metal, dismantling the discharge-tube, then introducing a new one and repeating the measurement. The fluctuation in value given by the same metal under successive tests of this kind was generally great enough to prevent a satisfactory comparison of the whole series. Neither were satisfactory results obtained by mounting the several metals in similar discharge-tubes and setting these up in open connexion with each other. A discharge passing through one tube produced often a much greater variation of the electrode fall in the neighbouring tubes than in the active one.

The scheme finally adopted, which proved wholly satisfactory, was to bring, in rapid succession, the metals to be tested into the same position in one discharge-tube and measure the electrode fall under invariable conditions, the results being discarded if a disturbing change took place in the gas during the series of observations.

Fig. 1 represents a vertical section of the discharge-tube ending below in a larger cylindrical chamber (axis vertical), the whole of glass construction. Ten electrodes $\mathbf{E}$ (circular disks $15 \mathrm{mms}$. in diameter) were attached to the face of a circular glass plate at equal intervals by hard rubber caps $K$ (see also plan in fig. 2). This glass plate, mounted in the cylindrical chamber, could be rotated about its axis by the key introduced through the ground joint $J$, and by this means any electrode brought into position at the lower end of the 
discharge-tube. A hard rubber disk, D, studded with brass rivets $\mathrm{C}$, and fixed to the circular plate, served to complete

Fig. 1.

Fig. 2.

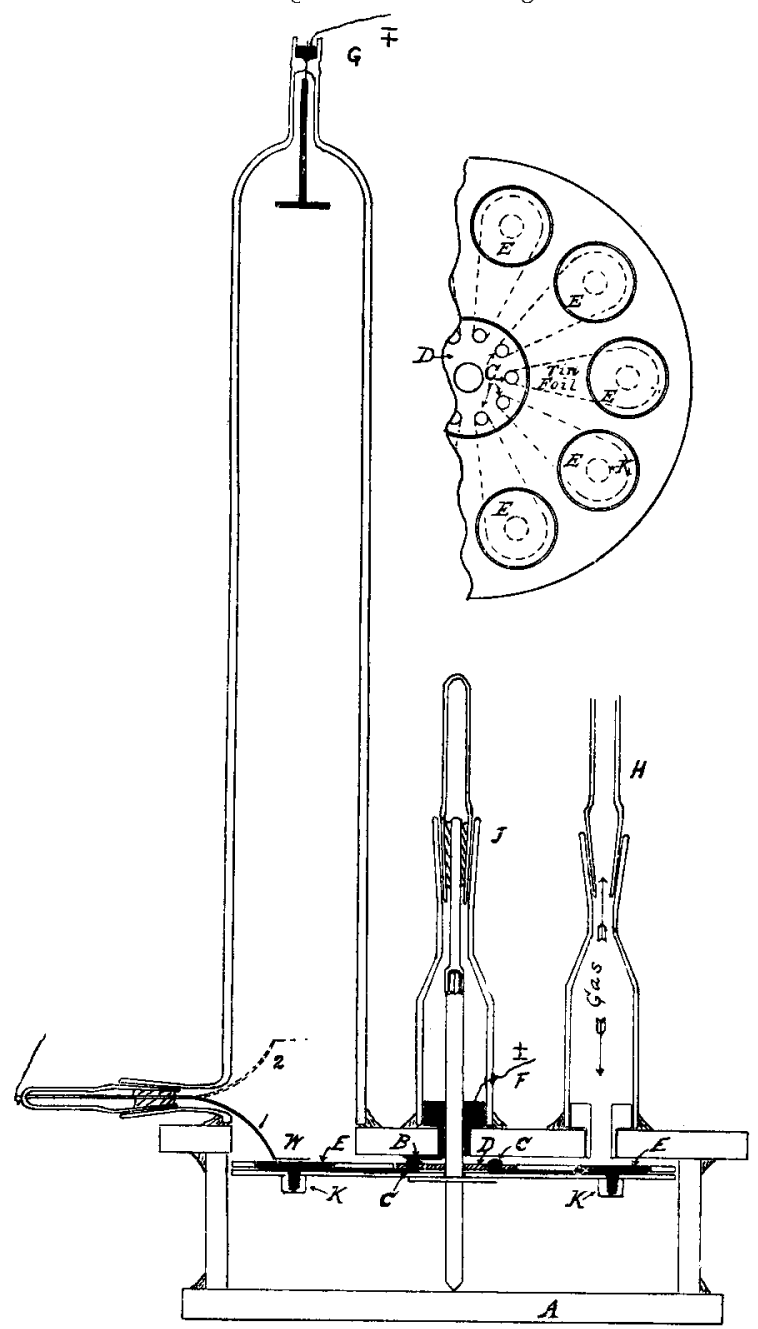

the felectric circuit from $F$ through the metal collar and attached spring-brush $B$ to the tinfoil strip leading to its corresponding electrode E. By this device all electrodes, with the exception of the one in use, were isolated from the

Phil. Mag. S. 6. Vol. 8. No. 45. Sept. 1904. 2 D 


\section{Prof. Skinner on the Relation of Electrode Fall}

circuit. To confine the discharge solely to the face of the electrode, a second circular glass plate properly cut was pressed closely on top of the first, covering the tinfoil strips and fitting the rim of the electrodes. Leakage from the brush $B$ to the gas was avoided by reducing the space between the upper face of the electrode-plate and the roof of the chamber to about $\frac{1}{2}$ millim. thickness. The discharge-tube was $3 \mathrm{cms}$. in diameter and about $20 \mathrm{cms}$. Iong. $\AA$ fine aluminium wire $W$, sheathed up to about 6 millims. of the end with fine glass tubing (outer diameter $\frac{1}{2}$ millim.), served at position 1 for obtaining the fall of potential at the anode. If turned into position $2,2 \frac{1}{2}$ centims. from the electrode, the same wire served for obtaining the cathode-fall, and, if desirable, the fall in the gas over the intervening, space. All permanent joints of this apparatus which could not be fused were cemented first with water-glass (sodium silicate), then, in addition, they were covered on the outside with de Khotinsky's laboratory-cement. The base-plate $A$, which bad to be removed to allow for repolishing the electrodes, was sealed by simply applying the latter cement on the outside of the juncture, care being taken that it did not extend to the inner part. This tube proved to be in all cases absolutely air-tight.

The platinum, gold, copper, lead, and aluminium electrodes were made from sheets as obtained commercially; silver and nickel from plates used in electroplating; bismuth, antimony, tin, cadmiun, zinc, and magnesium were cast. The steel electrodes were made of good tool-steel not hardened. All electrodes were given for each observation, when not otherwise designated, a fresh mirror-polish, using new felt as a polishing-cloth and new cotton-cloth for cleaning. As polishing material rouge was used for platinum, silver, and gold; but for the rest of the metals infusorial earth mixed with tallow proved more satisfactory, After polishing, the metals were very carefully cleaned by rubhing lightly with a dry cloth. They were then mounted quickly in the tube, which was immediately evacuated and flushed several times, and finally left standing in open connexion with a drying-chamber in a few millimetres of the gas. When the gas was dry the metals usually preserved their surface untarnished for several days-even in oxygen, lead excepted. At least two specimens of each metal were tested, but in no case was a notable difference in the different samples observed.

The gases were carefully prepared and stored in large flasks which had been previously cleaned, then dried and freed from occluded gas and moisture by standing highly exhausted 
several days in connexion with a drying-chamber containing phosphorus pentoxide. Pressure readings taken from day to day during this time indicated the rate at which occluded gas was given off. In these flasks mercury valves were used, so that while stored the gas came in contact with only glass and mercury. Observations made with treshly prepared hydrogen and that which had been stored for weeks were at no greater variance than those obtained from different tests with the stored gas.

Hydrogen was generated by electrolysis of dilute phosphoric acid; it was purified by passing through a solution of potassium permanganate, a tube containing pieces of caustic potash, another filled with phosphorus pentoxide, and finally through a chamber containing pure sodium to the storagechamber.

Nitrogen was obtained by passing air over heated phosphorus and through the same series as hydrogen.

Oxygen was obtained by heating a mixture of potassium chlorate and manganese dioxide. It was purified by passing through a solution of caustic potash, a tube containing sticks of the same, and finally a drying-tube of phosphorus pentoxide.

Gas-pressures were measured by means of a MacLeod gauge. The electric current was furnished by a battery of storage-cells and measured by a Weston milliammeter. A Kelvin quadrant-electrometer was used for the potential-measurements - the anode-fall being placed between the quadrants and a definite potential on the needle; the cathode-fall being placed on the needle and a definite potential between the quadrants. The anode-fall could be observed accurately to one-tenth volt; the cathode to less than one volt.

\section{Preliminary Tests.}

In hydrogen and oxygen a preliminary study of both cathode and anode fall was made, the controlling conditions in nitrogen* having been previously determined. The metals and discharge-tube were prepared and left over-night as described above. On the next day the tube was again flushed several times with the gas, great care being taken to avoid entrance of moisture through the pumping apparatus. Gas was finally let into the tube at the desired pressure, and after standing half an hour or more the fall of potential at the cathode (or anode) for the metals quickly observed-no metal

* Wied. Ann. lxviii. p. 752 (1899); Phil. Mag. l. e. 
being kept in use longer than wils absolutely necessary. This plan was followed throughout the investigation.

Cathode Fall in Hydrogen.-The cathode-fall in hydrogen, as in nitrogen $(l . c$.$) , increases for small currents in a linear$ manner with the current-density; it also increases, for the same current-density, as the gas-pressure diminishes-this latter, however, not in the simple manner found for nitrogen. Here also the rate of increase both with current-density and with decreasing gas-pressure is notably greater for those metals possessing the larger minimum, or normal, cathode-fall. In nitrogen the difference in fall between the metals is so small that this factor, though observable, was considered negligible. Observations in hydrogen are represented by curves in tig. 3 . They show the relation between the electric current and the cathode-fall for platinum, zinc, and aluminium-each with the gas at a pressure $1 \cdot 0,1 \cdot 72$, and $3 \cdot 0$ millims. of mercury. At each pressure the observations were made for all three metals without changing the gas. Those at the different pressures were also taken, in the sequence $1.72,3 \cdot 0$, and 1.0 millims., without in the meantime repolishing the electrodes. The sequence of observations for each curve, indicated by the arrows, shows the magnitude of the change wbich took place with use. This was always an increase, generally more rapid with those metals possessing the greater fall. The curves end on the left at about the minimum current-density, at which point the area of the discharge begins to contract with a further reduction of the current, and the cathode-fall becomes constant, as shown by the curve Al 1.72*. In addition to these, a set of observations were made at 2 mms. gas-pressure, comparing platinum and gold as cathodes. The difference in cathode-fall of these remained 5 volts throughout a range from 0.6 m.a. to 3 m.a. From these results it is to be concluded that the cathode series for hydrogen is the same whatever be the current-density and gas-pressure at which it be taken.

The Cathode Fall in Oxygen.-This exhibits the same qualities as hydrogen, with the interesting distinction that while the minimum cathode-fall is of about the same magnitude, its increase with current-density, and with diminishing

* While making these observations it was also noticed that the minimum current-density is smaller for the metal possessing the larger cathode-fall; for example, at $3.0 \mathrm{mms}$. pressure the discharge area for aluminium began to contract when the current was reduced below 1.3 m.a.; for zinc, below 0.8 m.a.; and for platinum, below 0.65 m.a. At lower pressures this transition-point becomes unobservable. 
gas-pressure, is strikingly less than for hydrogen. This is evident, when the curves for oxygen (fig. 4), taken at pressures 0.8 and $1.17 \mathrm{~mm}$, are compared with those for the same metals in hydrogen (fig. 3) at $1 \mathrm{~mm}$. pressure. This increase for oxygen is also smaller than for nitrogen, though the minimum fall for nitrogen is about 50 per cent. less than for oxygen.

Figु. 3.

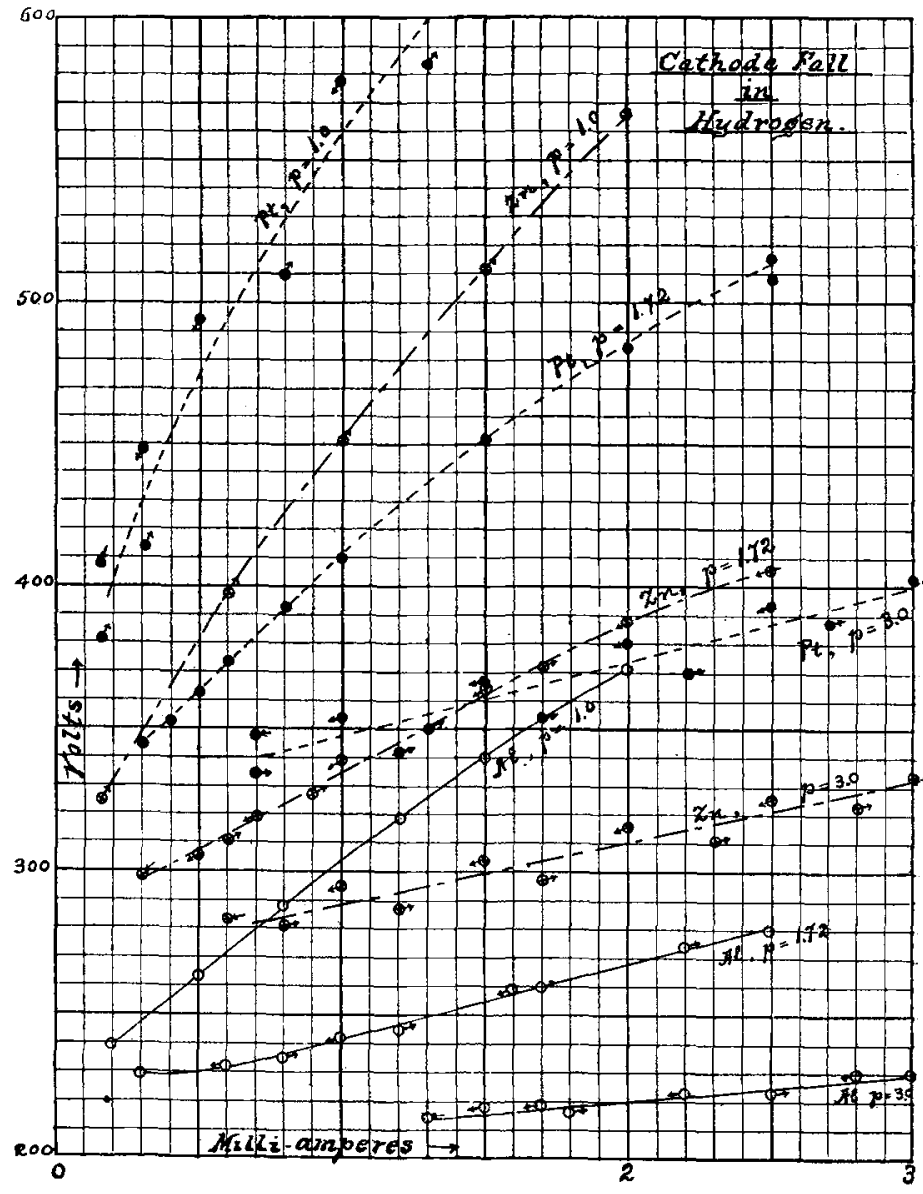

Of present interest, however, is the fact shown by the experiments with all three gases. The series of metals arranged according to the magnitude of the cathode-fall is the 
same whatever be the gas-pressure and current-density under which it be obtained.

Fig. 4.

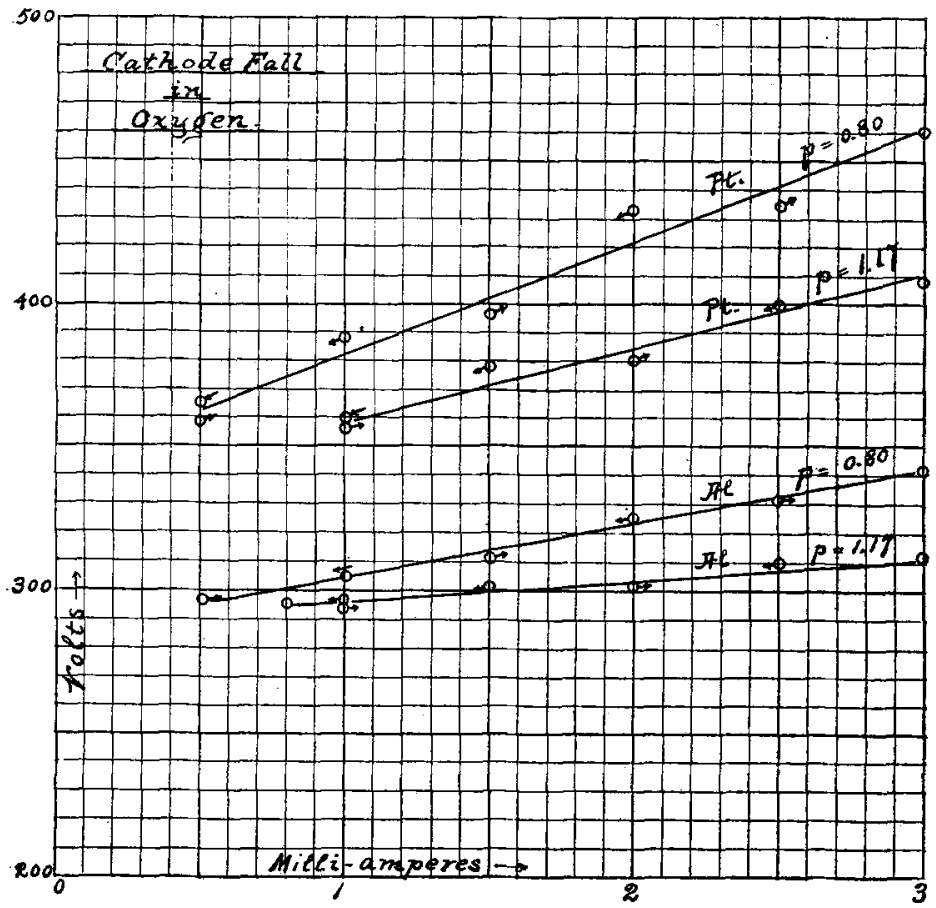

The Anode Fall. - In hydrogen and oxygen, as in nitrogen, the anode-fall for gas-pressures not lower than that giving an unstriated luminosity in the gas, is practically unaffected by changing the current-density. Earlier observations in nitrogen* indicated that the anode-fall increased with gaspressure-tests being always confined to conditions giving an unstriated luminosity in the gas. Similar experiments performed in hydrogen and in oxygen, however, indicate the anode-fall to be constant with increasing gas-pressure. These latter observations, placing the former results from nitrogen in question, called forth in the present investigation a caireful study of the anode-fall in this gas also. A notable difficulty in determining the anode-fall arises from the gas in the immediate vicinity of the anode possessing a potential gradient of negligible magnitude only at the lower pressures (approaching that giving the striated discharge). The observed

*Wied. Ann. $l$. $c$. 
fall may be partly made up of that in the gas in a region beyond a space covered by the real anode-fall. Since the potential gradient in the gas increases with the pressure, an observed increase in the anode-fall with the gas-pressure may then be attributed to this extra quantity. Such a view was strengthened on comparing the potential gradient in hydrogen and oxygen with that for nitrogen. Both hydrogen and oxygen were found to possess near the anode a gradient only about one-third the value of that observed for nitrogen. Thus we find the disturbing element with these gases considerably smaller than it is for nitrogen.

To obtain as nearly as possible the abrupt fall of potential between the anode and the gas, the test-wire W (fig. 1) was first adjusted parallel to and in contact with the face of the anode, giving a zero potential between them when the current was passing. Observing the electrometer, the wire was cautiously shifted out of contact, this being indicated by a sudden deflexion of the electrometer-needle. The smallest deflexion thus obtained was taken as measuring the anode-fall. The observations for the three gases are given in Table I. The

Table I.-Anode-Fall in Volts. Different Gas-pressures.

\begin{tabular}{|c|c|c|c|c|c|c|c|c|c|c|c|c|}
\hline Gas. & $\begin{array}{c}\text { Gas- } \\
\text { press. }\end{array}$ & Pt. & Ag. & An. & Cu. & Fe. & $\mathrm{Ni}$ & Sn. & $\mathrm{Pb}$ & Cd. & $\mathrm{Zn}_{\mathrm{n}}$ & Al. \\
\hline Hydrogen & & $\mid \begin{array}{l}19 \cdot 8 \\
19 \cdot 7\end{array}$ & $\begin{array}{l}20 \cdot 5 \\
20 \cdot 5\end{array}$ & $\begin{array}{l}22 \cdot 7 \\
22 \cdot 9\end{array} \mid$ & $\begin{array}{l}22 \cdot 8 \\
23.9\end{array}$ & $\begin{array}{l}22 \cdot \pi \\
22 \cdot 5\end{array} \mid$ & $\begin{array}{l}23 \cdot 0 \\
23 \cdot 3\end{array}$ & & {$\left[\begin{array}{l}22 \cdot 8 \\
23 \cdot 1\end{array} \mid\right.$} & $\begin{array}{l}237 \\
23 \cdot 7\end{array}$ & $\begin{array}{c}23 \cdot 6 \\
23 \cdot 6\end{array}$ & \\
\hline Nitrogen. & & & $\begin{array}{l}18 \cdot 6 \\
18 \cdot 8\end{array}$ & & $\begin{array}{l}19 \cdot 0 \\
19 \cdot 6\end{array}$ & $\begin{array}{l}19 \cdot 4 \\
19 \cdot 9\end{array} \mid$ & $\begin{array}{l}19.4 \\
199\end{array}$ & & & $\left|\begin{array}{l}19 \cdot 1 \\
20.2\end{array}\right|$ & & \\
\hline Oxyge & & $\begin{array}{l}22.2 \\
233\end{array}$ & & $\begin{array}{l}243 \\
24 \cdot 2\end{array} \mid$ & $\begin{array}{l}23.2 \\
0.4\end{array}$ & $23 \cdot 8$ & $\begin{array}{l}235 \\
236\end{array}$ & $\begin{array}{l}24 \cdot 2 \\
25 \cdot 4\end{array} \mid$ & ..... & $\left|\begin{array}{l}24 \cdot 2 \\
25 \cdot 6\end{array}\right|$ & $\ldots$ & $\begin{array}{l}239 \\
25.9\end{array}$ \\
\hline
\end{tabular}

metals having been prepared as usual, their anode-fall for the lower gas-pressure was observed, then without repolishing them it was observed again in the fresh gas at the higher pressure. Several different metals were tested for the purpose of eliminating from the conclusions the effect of a change produced by use. The results with hydrogen show for seven metals the same value at the two pressures used; for copper and lead there is about 5 per cent. increase in fall for 50 per cent. increase in gas-pressure, which is undoubtedly due to a change in the electrode surface. In oxygen, four metals give the same value at the two pressures observed, while four show an increase in value of the fall with pressure. From the fact that there is generally an increase in electrode 
fall with use, the conclusion is warranted that here, as in hydrogen, the unchanged values are the true ones. On the other band, nitrogen gives for all metals a greater fall at the higher pressure, there being an increase of about 3 per cent. in the fall with a 30 per cent. increase in the gas-pressure. This is smaller than that previously reported, yet the question as to the change with gas-pressure in nitrogen must still remain unsettled. For the present investigation, however, the above results at least show the anode series, like the cathode series, to be independent of the gas-pressure and current-density under which it may be obtained.

\section{The Electrode Series.}

In Hydrogen.-Observations were first made on the cathode. Using metals representing the contact series, preparations as already described were carried out. To facilitate the rapidity with which observations of the electrode fall were made, the contact-brush (B, fig. 1) was so arranged that the discharge could take place from the next metal used just before the circuit from the preceding one was broken. By this device, the current through the tube remained uninterrupted during the series of observations, and oscillation of the electrometerneedle avoided. This arrangement allowed the cathode-fall to be obtained in less than ten seconds after it was brought into action, which was generally advantageous as the cathodefall tended to increase under action of the current. For this reason also the fall was obtained by a single deflexion of the electrometer-needle from its zero position-the latter being observed at the beginning and at the end of a series. Several independent tests were made, and though there was a marked variation in the magnitude of the fall under the different tests, yet they agreed with one another in placing the metals in the same series. Steel gave extremely erratic values; it also increased in fall so rapidly under action of the current that no definite value could be ascribed to it*.

The results of three consecutive determinations of the cathode series are given in Table II., for each of which the metals were newly polished. They are arranged in the table according to their position in the contact-potential series $\dagger$. It is to be seen that, with the exception of gold, the cathode. fall decreases in going from the platinum to the aluminium

* For the same reason, tin could not be satisfactorily used as anode in either hydrogen or nitrogen.

† The potential series is taken from Jahn's Grundriss d. Elektrochemie, p. 4. The position of nickel is not given by Jahn; it is placed here as slightly less than bismuth, as obtained from Winkelmann's Handb. $d$. Physite, III. i. p. 119. 
end of the series. In hydrogen, then, our hypothesis concerning the cathode series is supported by the experimental results. Copper, tested in two other series of observations not here recorded, fell consistently between silver and nickel in both cases.

TABLE II.-Cathode-Fall. Metals compared. Current 1.0 m.a.

\begin{tabular}{|c|c|c|c|c|c|c|c|c|c|c|c|c|c|c|c|}
\hline Gas. & $\begin{array}{l}\text { Gas- } \\
\text { press. }\end{array}$ & Pt. & Ag. & Au. & $\mathrm{Cu}$. & Fe. & $\mathrm{Ni}$. & $\mathrm{Bi}$. & Sb. & Sn. & $\mathrm{Pb}$ & $\mathrm{Cd}$. & Zn. & Al. & $\mathrm{Mg}$. \\
\hline Hydrogen. & $\begin{array}{l}2 \cdot 03 \\
2 \cdot 01 \\
2 \cdot 00\end{array}$ & $\begin{array}{l}399 \\
392 \\
373\end{array}$ & $\begin{array}{l}406 \\
398 \\
380\end{array}$ & $\begin{array}{c}386 \\
361 \\
\ldots \ldots\end{array}$ & & & $\begin{array}{l}397 \\
386 \\
381\end{array}$ & & & $\begin{array}{l}389 \\
372 \\
378\end{array}$ & $\begin{array}{l}382 \\
366 \\
375\end{array}$ & $\begin{array}{l}359 \\
363 \\
375\end{array}$ & $\begin{array}{l}326 \\
326 \\
324\end{array}$ & $\begin{array}{l}269 \\
255 \\
252\end{array}$ & $\begin{array}{l}266 \\
251 \\
255\end{array}$ \\
\hline Nitrogen. & $\begin{array}{l}1 \cdot 23 \\
1 \cdot 25 \\
1 \cdot 24\end{array}$ & $\begin{array}{l}252 \\
260 \\
253\end{array}$ & $\begin{array}{l}258 \\
2644 \\
263\end{array}$ & $\mid \begin{array}{l}258 \\
264 \\
\ldots \ldots\end{array}$ & $\begin{array}{l}258 \\
264 \\
262\end{array}$ & $\begin{array}{l}255 \\
26 \\
258\end{array}$ & $\begin{array}{l}237 \\
243 \\
\ldots \ldots\end{array}$ & 254 & 255 & & $\left|\begin{array}{l}243 \\
240 \\
247\end{array}\right|$ & $\begin{array}{l}266 \\
270\end{array}$ & $\mid \begin{array}{l}265 \\
271\end{array}$ & $\begin{array}{l}217 \\
219 \\
219\end{array}$ & 228 \\
\hline Oxygen. & $\begin{array}{l}1 \cdot 21 \\
1.20 \\
1 \cdot 20\end{array}$ & $\begin{array}{l}362 \\
356 \\
360\end{array}$ & $\begin{array}{l}371 \\
367\end{array}$ & $\begin{array}{l}364 \\
358 \\
361\end{array}$ & $\begin{array}{l}350 \\
353 \\
354\end{array}$ & $\begin{array}{l}330 \\
336 \\
339\end{array}$ & $\ldots \ldots$ & $\begin{array}{l}364 \\
357\end{array}$ & 358 & $\ldots \ldots$ & $\mid \begin{array}{c}370 \\
370 \\
\ldots \ldots\end{array}$ & $\begin{array}{l}349 \\
346 \\
348\end{array}$ & \begin{tabular}{|l}
347 \\
345 \\
$\ldots$
\end{tabular} & $\begin{array}{l}302 \\
301 \\
305\end{array}$ & 294 \\
\hline
\end{tabular}

TABLE III.-Anode-Fall. Metals compared.

\begin{tabular}{|c|c|c|c|c|c|c|c|c|c|c|c|c|c|c|}
\hline Gas. & $\begin{array}{c}\text { Gas- } \\
\text { press. }\end{array}$ & Pt. & Ag. & Au. & $\mathrm{Cu}$. & Fe. & $\mathrm{Ni}$ & $\mathrm{Bi}$ & Sb. & $\sin$. & $\mathrm{Pb}$ & $\mathrm{Ca}$. & $\mathrm{Zn}$ & Al. \\
\hline Hydrogen. & $\begin{array}{l}1.73 \\
1.71 \\
1.70\end{array}$ & $\begin{array}{lll}18 & 0 \\
18 \cdot 4 \\
17 \cdot 3\end{array}$ & $\begin{array}{l}18.4 \\
18.8 \\
17.7\end{array}$ & $\left|\begin{array}{l}20 \cdot 1 \\
19 \cdot 5 \\
20 \cdot 7\end{array}\right|$ & $\begin{array}{l}18 \cdot 9 \\
19 \cdot 7 \\
20 \cdot 0\end{array}$ & $\begin{array}{l}22 \cdot 1 \\
18.5 \\
\ldots \ldots\end{array}$ & $\mid \begin{array}{l}19 \cdot 9 \\
19 \cdot 3\end{array}$ & $\begin{array}{l}19.9 \\
18.0 \\
18 .\end{array}$ & $\begin{array}{c}20.6 \\
\cdots \ldots . \\
\cdots \ldots .\end{array}$ & $\left|\begin{array}{l}20 \cdot 8 \\
\hdashline \ldots .0 \\
20.0\end{array}\right|$ & $20 \cdot 3$ & $\left|\begin{array}{c}207 \\
199\end{array}\right|$ & $\left|\begin{array}{l}20 \cdot 4 \\
20 \cdot 2 \\
19 \cdot 1\end{array}\right|$ & $20 \cdot 1$ \\
\hline Nitrogen. & $\begin{array}{l}1 \cdot 39 \\
1 \cdot 37\end{array}$ & \begin{tabular}{|l|}
$18 \cdot 8$ \\
$18 \cdot 5$
\end{tabular} & $\begin{array}{l}19 \cdot] \\
18 \cdot 6\end{array}$ & $\begin{array}{l}21 \cdot 1 \\
19 \cdot 9\end{array}$ & $\begin{array}{l}19 \cdot 7 \\
190\end{array}$ & $\begin{array}{l}19 \cdot 7 \\
19 \cdot 4\end{array}$ & $\begin{array}{l}203 \\
19 \cdot 4\end{array}$ & & & & $\begin{array}{l}20 \cdot 6 \\
20 \cdot 0\end{array}$ & $\begin{array}{l}19 \cdot 7 \\
19 \cdot 1\end{array}$ & $\begin{array}{l}19 \cdot 6 \\
18 \cdot 5\end{array}$ & \begin{tabular}{r|}
$22 \cdot 2 \cdot$ \\
$21 \cdot 9$
\end{tabular} \mid \\
\hline Oxygen. & $1-20$ & $22 \cdot 2$ & & $24 \cdot 3$ & $|23 \cdot 2|$ & $23 \cdot 8$ & $23 \cdot 5$ & & 235 & $24 \cdot 2$ & $\ldots \ldots$ & $|24 \cdot 2|$ & & $23 \cdot 9$ \\
\hline
\end{tabular}

The Anode Fall.-Three similar sets of observations of the anode-fall in hydrogen are recorded in Table III. The fall for most metals remaining very constant under the action of the current, it was measured more deliberately than the cathode-fall as a mean of the "right" and "left" deflexions of the electrometer-needle. Here we find in general the anode series to be the reverse of that of the cathode; that is, the reverse potential series. Gold, however, is high here, while it is low in the cathode series. The values for steel fluctuate considerably, and for magnesium the anode-fall for all gases increases so rapidly with use that it was impossible to obtain a reliable value for it.

The Electrode Fall in Nitrogen and Oxygen-In Table II. 


\section{Prof. Skinner on the Relation of Electrode Fall}

are also given the results of observations on the cathode-fall in nitrogen and in oxygen; in Table III. correspondingly the anode-fall. In nitrogen, the cathode, anode, and potential series are consistent with each other for eleven metals; but in relation to the potential series the cathode-fall for cadmium and zinc is abnormally high, while the anode-fall for these metals is correspondingly low. In nitrogen, tin increased with use so rapidly that its value as an electrode could not bo reliably fixed.

In oxygen, results were duplicated with a greater degree of accuracy than in either hydrogen or nitrogen. The electrode series is in the main consistent with the potential series, steel and nickel being marked exceptions. The high value of the cathode-fall for lead is attributed to its surface becoming tarnished while standing in the gas. Silver, which maintains a high polish in the inactive gas, was vigorously attacked by it when an electric discharge was passed through the tube. Though it was isolated from the electric circuit, its surface turned a rich brown colour in less than ten seconds after the discharge started. Its cathode-fall was constant, and about

Fig. $\overline{5}$.

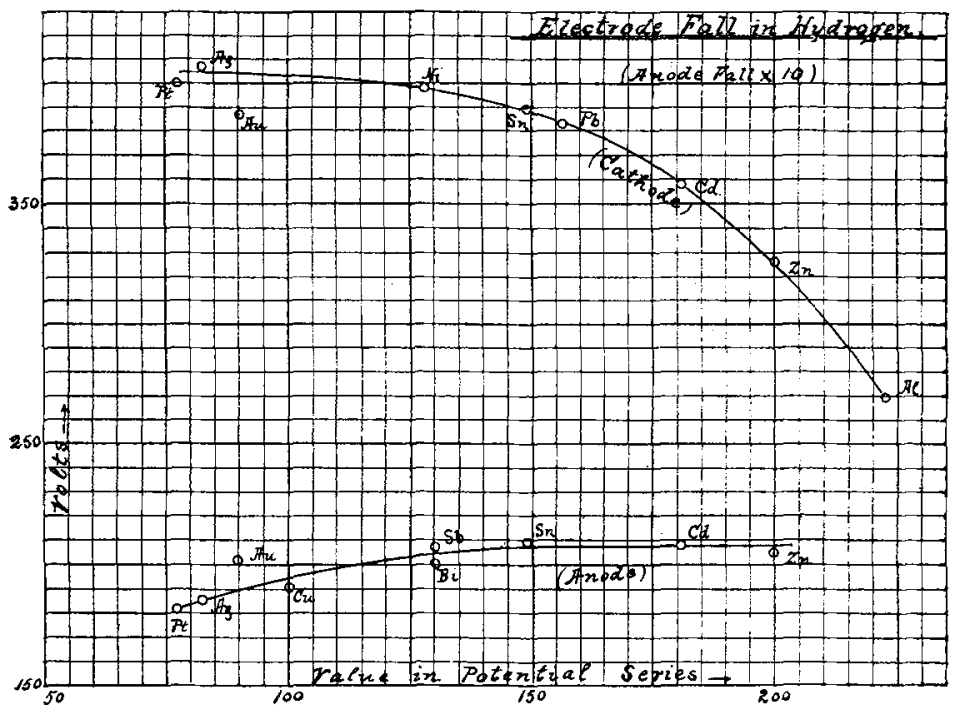

the same as that given by lead. With bismuth a more striking phenomenon occurred. Isolated in the conducting gas or used as cathode, its polish was maintained; but the moment it served as anode its surface darkened as rapidly as 
did that of silver. The anode-fall increased rapidly with this change.

To facilitate comparison, the variation of electrode fall with the contact potential of the metal in the different gases is represented by curves in figs. 5, 6, and 7. These are taken

Fig. 6.

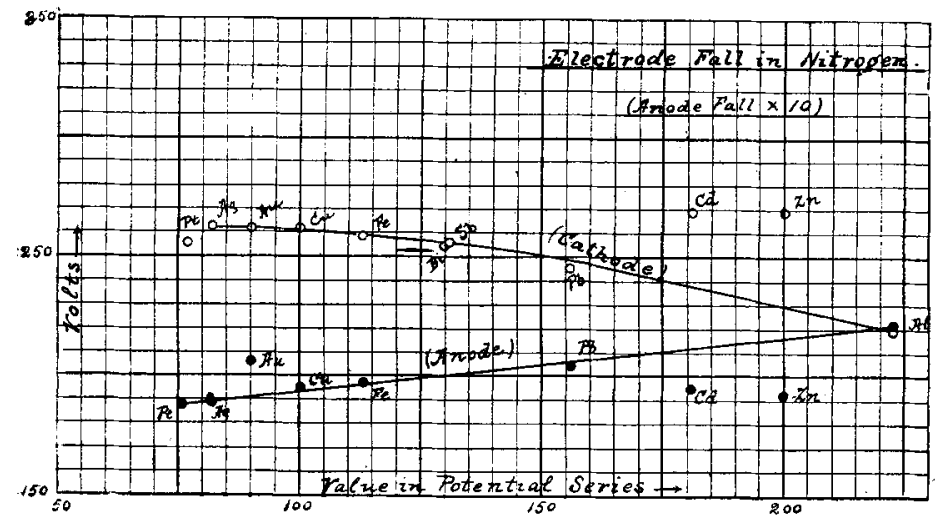

Fig. 7.

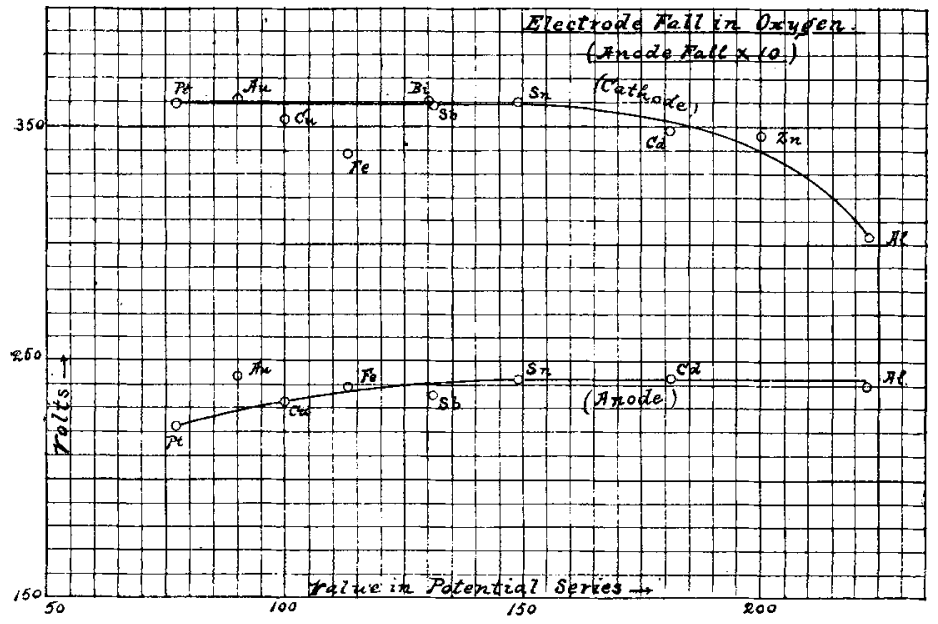

from the observations given in Tables II. and III. In each figure the abscissæ represent the value of the metal in the contact-potential series (copper being given the value 100, zinc 200). The ordinates represent in the upper curve the 
corresponding cathode-fall; in the lower, the anode-fall multiplied by 10 .

Our hypothesis appears to be supported throughout by the experimental results. The electrode fall may be represented as a continuous function of the contact potential of the electrode. The curves show some interesting exceptions. Platinum exhibits a slight tendency to drop below its normal value as cathode, but is in line as anode. Gold appears in general to be displaced in the electrode series to the neighbourhood of tin and lead. This is ascribed to the effect of mercury-vapour in that the surface of the gold always bleached while standing in vacuo. Gold-foil interposed between the discharge-tube and the parts containing mercury did not prevent this bleaching effect. Being heated to redness, the metal regained its natural tint.

In nitrogen, cadmium and zinc are displaced to the platinum end in the electrode series, the cathode-fall, as already noted, being for these metals abnormally high, while the anode-fall is abnormally low.

In oxygen, copper drops as cathode slightly below its normal position; but steel and nickel form interesting exceptions in being displaced to the vicinity of zine in the electrode series. A similar inconsistency is exhibited by these metals when the potential series in sulphuric acid and that given by the heat of combination of the metals with it are compared*.

In conclusion, it should be remarked that, as shown by these curves, the electrode fall is not a constantly increasing quantity in passing from one end of the potential series to the other; but that, starting with a minimum value at one end, it approaches at a decreasing rate a constant maximum value for the rest of the series. This is clearly marked for all curves except that giving the anode-fall in nitrogen.

April, 1904.

XXXIX. The Effeet of a Luminous Discharge on the Ionization produced by Hot Platinum in Gases at Low Pressures. $B y$ O. W. Richardson, M.A., D.Sc., Fellow of Trinity College and Clerk Maxwell Student in the University of Cambridget.

T THE present communication forms the continuation of an investigation the results of which were embodied in a paper read before the Physical Society on June 12, 1903, and published in the Philosophical Magazine for the following

* Jahn's Grundriss d. Elektrochemie, p. 7.

$\uparrow$ Communicated by the Author. 